\title{
Comparison of the specificity of cardiac troponin I and creatine kinase MB in isoproterenol-induced cardiotoxicity model in rats
}

\author{
Eliška Kolmanová ${ }^{1}$, Ladislava Bartošová ${ }^{1}$, Elian Khazneh², Tomáš Parák ${ }^{1}$, Pavel Suchý1 \\ University of Veterinary and Pharmaceutical Sciences, Faculty of Pharmacy, ${ }^{1}$ Department of Human \\ Pharmacology and Toxicology, ${ }^{2}$ Department of Natural Drugs, Brno, Czech Republic
}

Received March 17, 2015

Accepted September 23, 2015

\begin{abstract}
The aim of this study was to implement the determination of cardiac markers in preclinical research at our department. For this purpose, the pathophysiological model of acute cardiotoxicity induced by high doses of isoproterenol was used. Isoproterenol hydrochloride was intraperitoneally administrated to 42 Wistar male rats at a dose of $50 \mathrm{mg} / \mathrm{kg}$ body weight. Cardiac injury was determined by assessing the concentrations of the cardiac markers (cTnI - cardiospecific troponin I and CKMB - cardiac isoenzyme creatine kinase) in the blood at predetermined time-intervals $(2,4,6,12,24$ and $36 \mathrm{~h})$, and confirmed by ECG. Isoproterenol hydrochloride caused an elevation in the plasma concentrations of both markers. The results showed a significant difference $(P<0.01)$ in the concentrations of cTnI between the experimental and control groups at 2, 4, 6 and $24 \mathrm{~h}$ with a maximum peak between the fourth and sixth hour. However, the difference in the concentrations of CKMB between the experimental and control groups was non-significant. This experiment confirmed that cTnI is more cardiospecific than CKMB. It also revealed the possibility to use this marker in preclinical testing.
\end{abstract}

Acute cardiotoxicity, cardiac markers, cardiospecificity, in vivo experiment

All the biomarkers that have been used in cardiology are involved in the contraction or energy metabolism of the heart tissue. Transaminases and lactate dehydrogenase lack a high specificity to the cardiac tissue; creatine kinase was used for a long time as a marker of choice, but it is of low cardiospecificity. Nowadays, more specific troponins are used and they play a great role in clinical medicine (Ladens on 2007).

Troponin (Tn) is a regulatory protein that forms a complex located in the contractile apparatus of the muscle tissue. It consists of three subunits $(C, T$, and $I)$ that differ in the role they play in the interaction between actin and myosin filaments (Adamcova et al. 1999; Parmacek et al. 2004). Although troponin is present in both skeletal and cardiac tissues, cardiac isoforms (cTnI and cTnT) have a unique composition of amino acids, which gives them a high specificity to the myocardium. Troponin $\mathrm{C}$, however, is not a cardiospecific marker due to its identical amino acid sequence in the skeletal and cardiac muscles (Schreier et al. 1990; Hamm et al. 1998).

Damage of the cardiomyocytes is manifested by the release of inner proteins out of the cells. Troponin I and T have two pools in the cells: the majority are bound to actin filaments in the myofibrils, whereas a free form is found in the cytoplasm. In case of cell death, free proteins in the cytoplasm leave the cell more rapidly than the ones fixed in the myofibrils. Troponin T has two considerable pools, thus its release kinetics is biphasic. The cytosolic pool of cTnI is considerably smaller and therefore the release of this protein is more likely to be monophasic (Katus et al. 1991; Korff et al. 2006).

Cardiospecific isoforms of troponin (cTnT and cTnI) are nowadays used as the gold standard for the diagnosis and risk stratification of patients with acute coronary syndrome and heart failure. The use of troponin in veterinary medicine and preclinical research is

Address for correspondence:

PharmDr. Eliska Kolmanova

Department of Human Pharmacology and Toxicology

Faculty of Pharmacy

University of Veterinary and Pharmaceutical Sciences Brno

Palackého tř. 1/3, 61242 Brno, Czech Republic

Phone: +420 541562896

E-mail: kolmanovae@vfu.cz

http://actavet.vfu.cz/ 
growing. The highly preserved structure and function of troponins across animal species offer the option to employ the determination of troponins in preclinical research using highly sensitive human immunoassay kits (O'Brien et al. 1997; Wells et al. 2008). Their greatest potentials are seen in the development of myocardial protective strategies or predicting the cardiotoxicity of new chemical substances in animal models.

Creatine kinase, or more precisely, its cardiac isoenzyme (CKMB) is used as an alternative to cardiac troponins, but it lacks high specificity to the myocardium due to its presence in the skeletal muscles. This enzyme is involved in the regulation of high-energy phosphate production and utilization within contractile tissues (Bessman et al. 1985).

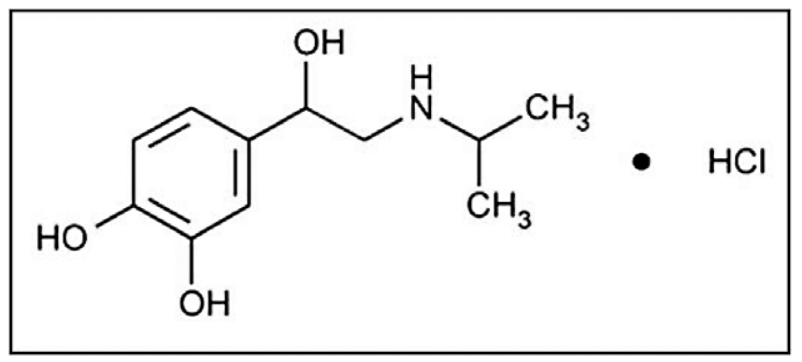

Fig. 1. The chemical structure of isoproterenol hydrochloride

Isoproterenol (ISO) is a catecholamine that belongs to the beta sympathomimetic agonists with a non-selective effect on both beta1- and beta2-adrenergic receptors (Fig. 1). High doses of isoproterenol are known to induce myocardial infarction in laboratory animals (Rona et al. 1959; Filho et al. 2011). The necrosis induced by ISO is mainly located in the subendocardial region of the left ventricle and the interventricular septum (Chappel et al. 1959). The mechanism of cardiac impairment caused by ISO is not clear and appears to be complex. Oxidative stress is probably one of the main causes (Tappia et al. 2001; Ojha et al. 2010). The positive inotropic and chronotropic effects of ISO at high doses lead to a depletion in the myocardial energy reserves, and thus result in biochemical and structural changes that may be responsible for the development of cardiac injury (Mahammad Rahmathulla et al. 2013). There are some newly accepted explanations describing tissue damage caused by ISO on a different molecular level, e.g. the effect of ISO on the dystrophin-glycoproteins complex which stabilizes the integrity of the sarcolemma of cardiomyocytes (Campos et al. 2008).

The aim of this experiment was to observe the kinetics of $\mathrm{cTnI}$ and CKMB in isoproterenolinduced cardiotoxicity model and to compare their cardiospecificity in laboratory rats.

\footnotetext{
Materials and Methods

Animals

The experiment was performed in vivo on 42 male Wistar rats. The animals were purchased from Anlab Ltd., Prague, Czech Republic. They were bedded on wood shavings and given a standard diet (diet for small laboratory animals M1) and water ad libitum. The temperature and humidity were in accordance to the conditions specified in Decree No. 419/2012 Coll. The experimental protocol was approved and monitored by the Ethics Committee of the University of Veterinary and Pharmaceutical Sciences (No. 5-2013 according to the Act No. 246/1992 Coll).

The rats were randomly divided into 6 groups. Each group had five rats forming the experimental part and two rats as the control part. The groups differed from each other in times of blood collection $(2,4,6,12,24$ and $36 \mathrm{~h}$ ). The animals were anaesthetized by subcutaneous administration of a mixture of tiletamine and zolazepam
} 
(Zoletil ${ }^{\circledR}$ plv. Virbac Co.) that was dissolved in aqua pro injectione, at a dose of $80 \mathrm{mg} / \mathrm{kg}$ body weight (b.w.). After blood collection, the animals were sacrificed by intrathoracic application of T61 ${ }^{\circledR}$ (solution of embutramid, mebezonium iodide, and tetracaine hydrochloride, Intervet Co.).

Isoproterenol

Isoproterenol (ISO) (Isoproterenol Hydrochloride, Sigma-Aldrich Co.) was dissolved in an isotonic $0.9 \% \mathrm{NaCl}$ solution (sterile saline solution). The appropriate way of administration and dose of ISO were chosen based on a pilot study from 2012 (Table 1). Isoproterenol was administered intraperitoneally at a dose of $50 \mathrm{mg} / \mathrm{kg}$ b.w. to animals named as ISO animals. The control animals were treated with pure $0.9 \% \mathrm{NaCl}$ administered by the same route.

Table 1. Isoproterenol-induced cardiotoxicity. Results of a pilot study performed previously.

\begin{tabular}{lcccr}
\hline & Administration & $\mathrm{n}$ & Dosage & Mortality (\%) \\
\hline Group 1 & s. $c$. & 5 & $100 \mathrm{mg} / \mathrm{kg} \mathrm{b.w.}{ }^{(1)}$ & 100 \\
Group 2 & $i . p$. & 3 & $50 \mathrm{mg} / \mathrm{kg} \mathrm{b.w.}{ }^{(2)}$ & 0 \\
Group 3 & $i . v$. & 4 & $4 \mathrm{mg} / \mathrm{kg} \mathrm{b.w.}{ }^{(3)}$ & 50 \\
Control group & s. $c$. & 1 & ------------------ & 0 \\
& $i . p$. & 1 & -------- & 0 \\
\hline
\end{tabular}

$\mathrm{n}$ - the number of animals in each group differs with different routes of ISO administration

dosage - the dose of ISO was chosen based on the toxicological data in the mentioned references:

${ }^{(1)}$ Hasić et al. 2011; (2) York et al. 2007; (3) O’Brien et al. 2006

The easiest manipulation and the lowest mortality were shown in group 2

\section{Cardiac markers (cTnI, CKMB)}

Blood samples were taken from vena jugularis and centrifuged for 5 min at RCF $1523 \times g$. Plasma was frozen and stored at $-80^{\circ} \mathrm{C}$. The final determination was carried out on the biochemical analyser Dimension ExL (Siemens Co.) using LOCI (Luminescent Oxygen Channeling Immunoassay) to assess the concentrations of cTnI, and absorption photometry to assess the concentrations of CKMB. Both markers were assessed in each plasma sample; CK-MB concentrations were measured in $\mu \mathrm{kat} / \mathrm{l}$ and $\mathrm{cTnI}$ concentrations in $\mathrm{ng} / \mathrm{ml}$ units.

\section{ECG monitoring}

Besides assessing the concentrations of cardiac markers, ECG (ECG Seiva Praktik Veterinary, Czech Republic) was also used as another indicator to detect the cardiotoxicity of ISO. ECG was recorded $2 \mathrm{~h}$ after the administration of ISO or $0.9 \% \mathrm{NaCl}$ sol. The parameters used to record the ECG were $50 \mathrm{~mm} / \mathrm{s}$ and $20 \mathrm{~mm} / \mathrm{mV}$.

\section{Statistical analysis}

Statistical analysis was performed using the statistical program Unistat 5.1. Non-parametric Mann-Whitney $U$ test was used. The results are summarized in figures and tables. Significance was determined at $P<0.01$.

\section{Results}

The mean weight of animals was $241.0 \pm 16.4 \mathrm{~g}$. Table 2 summarizes the allocation of animals into groups, numbers of ISO and control animals, and mortality during the experiment. Differences in the concentrations of cTnI between ISO animals and control animals were significant at several time intervals $(2,4,6,24 \mathrm{~h})(P<0.01)$, whereas differences in the concentrations of CK-MB were non-significant $(P>0.01)$. There was also a difference in the kinetics of these 2 markers. Troponin showed an early onset and a more monophasic release with the maximum peak between the fourth and sixth hour. The concentrations of CKMB showed a decline in the beginning followed by an increase that continued till the end of measurement.

Table 3 presents the mean concentrations of cTnI $(\mathrm{ng} / \mathrm{ml})$ and CK-MB $(\mu \mathrm{kal} / \mathrm{l})$ detected in plasma at predetermined time intervals for each group. These results are also demonstrated in Figs 2 and 3. Figure 4 shows the ECG recordings of two animals $2 \mathrm{~h}$ after the i.p. 
Table 2. The allocation of animals into groups and mortality during the experiment.

\begin{tabular}{lccccc}
\hline ISO $i . p$. & Time (hours) & $\mathrm{n}_{1}$ & $\mathrm{n}_{2}$ & Mean weight $(\mathrm{g})$ & Mortality $(\%)$ \\
\hline Group 1 & 2 & 5 & 2 & $249.3 \pm 9.1$ & 0 \\
Group 2 & 4 & 5 & 2 & $240.4 \pm 7.0$ & 0 \\
Group 3 & 6 & 5 & 2 & $238.9 \pm 12.2$ & 0 \\
Group 4 & 12 & 5 & 2 & $216.6 \pm 14.2$ & 0 \\
Group 5 & 24 & 5 & 2 & $245.3 \pm 13.5$ & 0 \\
Group 6 & 36 & 5 & 2 & $255.3 \pm 7.1$ & 0 \\
\hline
\end{tabular}

Time - predetermined time intervals of blood collection; $\mathrm{n}_{1}-$ number of ISO animals; $\mathrm{n}_{2}-$ number of control animals; the mean weight $(\mathrm{g})$ is expressed as mean $\pm \mathrm{SD}$

Table 3. The mean values of cTnI and CKMB in isoproterenol (ISO) and control animals.

\begin{tabular}{lcccr}
\hline ISO $i . p$. & \multicolumn{2}{c}{ cTnI $(\mathrm{ng} / \mathrm{ml})$} & \multicolumn{2}{c}{ CK-MB $(\mu \mathrm{kat} / \mathrm{l})$} \\
\cline { 2 - 5 } $50 \mathrm{mg} / \mathrm{kg}$ b.w. & Experimental part & Control part & Experimental part & Control part \\
\hline Group 1 & $8.69 \pm 4.12$ & $0^{1} ; * *$ & $17.67 \pm 2.38$ & $15.11 \pm 4.50$ \\
Group 2 & $12.63 \pm 8.68$ & $0^{1} ; * *$ & $12.02 \pm 2.98$ & $8.59 \pm 0.07$ \\
Group 3 & $12.45 \pm 7.22$ & $0^{1} ; * *$ & $16.49 \pm 3.93$ & $12.36 \pm 0.49$ \\
Group 4 & $1.59 \pm 1.08$ & $0^{1}$ & $12.30 \pm 3.94$ & $8.39 \pm 0.38$ \\
Group 5 & $2.01 \pm 0.58$ & $0^{1} ; * *$ & $11.58 \pm 3.57$ & $9.38 \pm 1.68$ \\
Group 6 & $0.36 \pm 0.14$ & $0.02 \pm 0.02$ & $16.81 \pm 7.03$ & $17.75 \pm 1.81$ \\
\hline
\end{tabular}

${ }^{1}$-LoD (limit of detection) of the assay used was $0.017 \mathrm{ng} / \mathrm{ml}$; values of the markers are expressed as mean $\pm \mathrm{SD}$; groups are divided into two parts: experimental part (ISO animals) and control part (control animals) **-significance $(P<0.01)$ in the differences between control and experimental parts

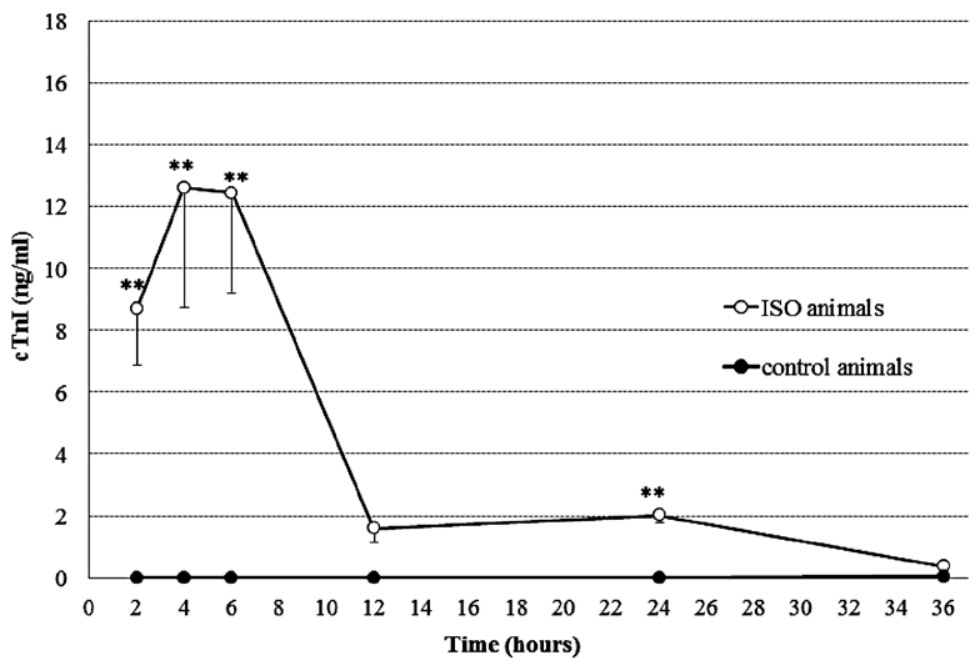

Fig. 2. Plasma concentrations of $\mathrm{cTnI}(\mathrm{ng} / \mathrm{ml})$ measured at predetermined time intervals

Time 0 - the application of ISO at a dose of $50 \mathrm{mg} / \mathrm{kg}$ b.w.; the subsequent time intervals refer to the times of blood collection;

** - significance $(P<0.01)$ in the differences between ISO and control animals; concentrations of cTnI in the ISO animals are expressed as mean $\pm \mathrm{SD}$; concentrations of $\mathrm{cTnI}$ in the control group were negligible or very low 


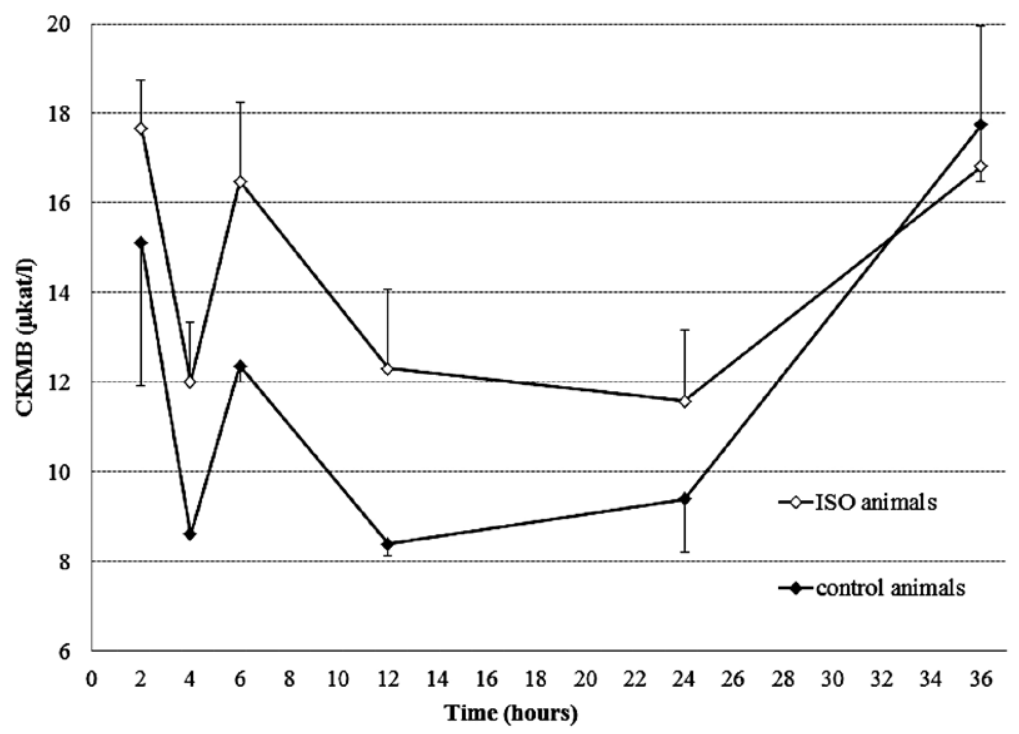

Fig. 3. Plasma concentrations of CK-MB ( $\mu \mathrm{kat} / \mathrm{l})$ measured at predetermined time intervals

Time 0 - the application of isoproterenol at a dose of $50 \mathrm{mg} / \mathrm{kg}$ b.w.; the subsequent time-intervals refer to the times of blood collection; concentrations of CKMB in ISO animals are expressed as mean $\pm \mathrm{SD}$; the differences in concentrations of CKMB between ISO and control animals were non-significant

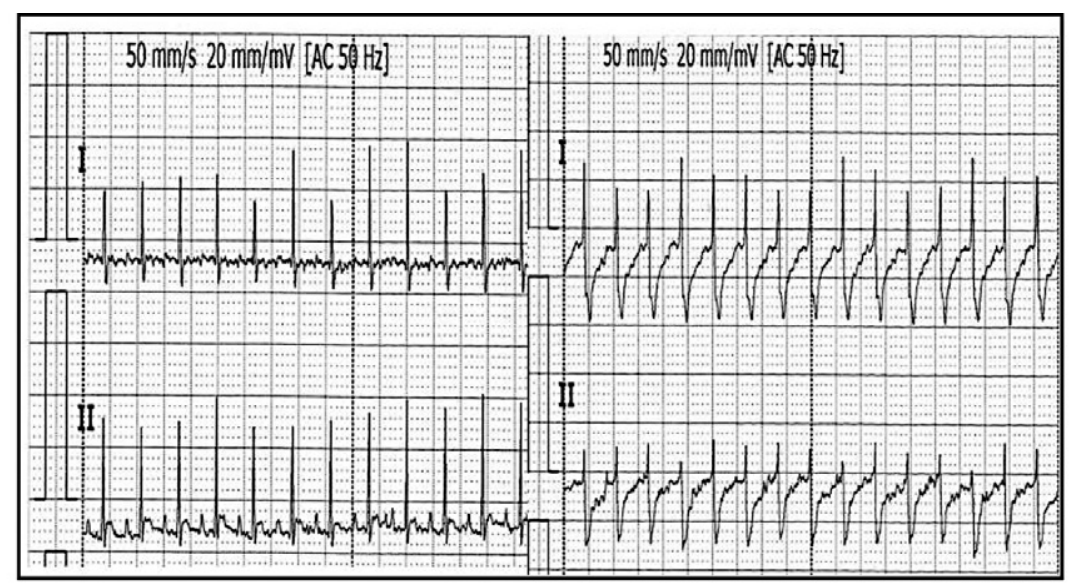

Fig. 4A

Fig. 4B

Fig. 4. ECG record of control (4A) and isoproterenol animal (4B) at $2 \mathrm{~h}$ after i.p. administration of $0.9 \% \mathrm{NaCl}$ sol. (4A) or ISO (4B).

The depression of the ST segment shown in Fig. 4B demonstrates the effect of ISO on the cardiac tissue and correlates with subendocardial ischaemia.

administration of $0.9 \% \mathrm{NaCl}$ sol. (Fig. 4A) and ISO (Fig. 4B). Figure 4B shows the ST segment (area starting at the $\mathrm{J}$ point and ending at the beginning of the $\mathrm{T}$ wave on ECG record) depression with negative deflection. 


\section{Discussion}

Troponins, especially their cardiac isoforms, cTnI and cTnT, are widely used in human medicine for the detection of cardiac damage. These proteins play an important role in muscle contraction, and leave the intracellular environment of cardiomyocytes in the case of structural impairment of the heart caused by, e.g. ischaemia, cardiotoxic agents, etc.

Bertinchant et al. (1996) showed the high specificity of cTnI in human medicine and described this protein to be a suitable marker for an early and late diagnosis of acute myocardial infarction. Our experiment was based on the results of a pilot study and focused on obtaining detailed knowledge of the kinetics of cardiac enzymes (cTnI, CKMB). In addition, the goal was to optimize a method for future experiments and devise a complete model of acute isoproterenol-induced cardiotoxicity in rats.

Recently, efforts have been made to employ troponins in preclinical safety testing where they show a wide range of uses. Reagan (2010) discusses the future of troponins especially in drug development. Troponins represent a specific and sensitive tool for the assessment of cardiac damage as well as cardioprotective properties in studies where the tested substance has potential effects on the cardiac tissue.

An undoubted positive attribute of troponins is their highly preserved structure $(\mathrm{O}$ ' Brien et al. 1997). The algorithm BLASTp (Basic Local Alignment Search Tool proteins) reports a $93 \%$ similarity in the structure of cardiac troponin I between humans and rats. The cardiac isoform of creatine kinase (CKMB) was used for a long time as a marker of choice before the era of troponins. Nowadays it is only used as an alternative to troponins or in combination.

High doses of isoproterenol lead to structural and biochemical changes in the cardiomyocytes, and energy imbalance through the activation of the beta sympathomimetic system (Rona 1985). The area that is most susceptible to hypoxia is the left ventricular subendocardium (Chapel et al. 1959; Zhang et al. 2008). Subendocardial (nontransmural) ischaemia is associated with a depression in the ST segment in human and animal models (Mirvis et al. 1986, Potse et al. 2007). This corresponds with our findings and confirms the cardiotoxicity of ISO at a dose of $50 \mathrm{mg} / \mathrm{kg} \mathrm{b.w}$.

The higher cardiospecificity of cTnI in comparison to CKMB demonstrated in our study is consistent with other publications dealing with the same issue in human medicine (e.g. Apple 1999) and preclinical research (e.g. Walker 2006). In our study, the myocardial specificity of cTnI was proven by the significant differences in the concentrations of cTnI between ISO animals and control animals at several time intervals (2, 4, 6, and $24 \mathrm{~h})$.

One detected maximum peak at four hours indicates a more monophasic kinetics of cTnI and reflects the fact that cTnI is primarily bound to the contractile apparatus with a negligible cytosolic pool. This fact was reported by Wu et al. (1998) who pointed out to a different amount of free cTnI and cTnT in the cytoplasm, and highlighted the variance in their release from the cardiomyocytes.

York et al. (2007) described a peak of plasma cTnI concentrations at $2 \mathrm{~h}(4.3 \mu \mathrm{g} / \mathrm{l})$ after the intraperitoneal use of isoproterenol at a dose of $50 \mathrm{mg} / \mathrm{kg} \mathrm{b}$.w. determined by ACS:80SE. On the other hand, another immunoassay (Immulite 2000) in the same study showed a maximum peak of cTnI concentrations one hour after the administration of ISO at a much lower concentration $(0.48 \mu \mathrm{g} / \mathrm{l})$. In our study, the concentration of cTnI was at its highest at the fourth hour after the administration of ISO $(12.6 \mu \mathrm{g} / \mathrm{l})$. We can speculate about the influence of the anaesthesia or immunoassay used on the difference in concentrations of cTnI in these studies. Lack of uniformity in the assays is one of the few negative attributes of troponins.

Creatine kinase MB was present at significant concentrations in both ISO and control animals. Due to the non-significant differences in the concentrations of this marker between 
ISO animals and control animals, we can regard CKMB as a cardiac damage indicator of low specificity. The high concentrations of CKMB in control animals were probably caused by tissue injury during the invasive procedure (the access to vena jugularis), due to the presence of this isoenzyme in the skeletal muscles (Wu et al. 1992), especially the thoracic muscles.

It is important to realize that these cardiac markers do not inform about the aetiology or pathogenesis of a disease. They only reflect the final stage, and their concentrations in the blood correlate with the size of the cardiac injury. This fact limits the use of troponins in the differential diagnosis of cardiac damage, but on the other hand, it enables a wide range of use in clinical and preclinical research.

Our findings have expanded the possibility of preclinical testing of newly-synthesized substances on cardiac tissue. They have enabled the use of isoproterenol-induced acute cardiotoxicity model in assessing the cardioprotective properties of chemical substances by measuring the concentrations of troponin I.

\section{References}

Adamcova M, Pelouch V 1999: Isoforms of troponin in normal and diseased myocardium. Physiol Res 48: 235-248

Apple FS 1999: The Specificity of Biochemical Markers of Cardiac Damage: a Problem Solved. Clin Chem Lab Med 37: 1085-1089

Bertinchant JP, Larue C, Pernel I, Leedermann B, Fabbro-Peray P, Beck L, Calzolari CH, Trinquier S, Nigond J 1996: Release kinetics of serum cardiac troponin I in ischemic myocardial injury. Clin Biochem 29: 587-594

Bessman SP, Carpenter CL 1985: The creatine-creatine phosphate energy shuttle. Annu Rev Biochem 54: 831-862

Campos EC, Romano MMD, Prado CM, Ross MA 2008: Isoproterenol induces primary loss of dystrophin in rat hearts: correlation with myocardial injury. Int J Exp Path 89: 367-381

Chappel CL, Rona G, Balazs T, Gaudry R 1959: Severe myocardial necrosis produced by isoproterenol in the rat. Arch Int Pharmacodyn Ther 122: 123-128

Filho HGL, Ferreira NL, de Soresa RB, de Carvalho ER, Lobo PLD, Filho JGL 2011: Experimental model of myocardial infarction induced by isoproterenol in rats. Rev Bras Cir Cardiovasc 26: 469-476

Hamm CW, Katus HA 1995: New biochemical markers for myocardial cell injury. Curr Opin Cardiol 10: 355-360

Hasić S, Jadrić R, Kiseljaković E, Valjevac A, Mornjaković Z, Winterhalter-Jadrić M 2011: Time-dependent responses of rat troponin I and cardiac injury following isoproterenol administration. Medicinski Glasnik 8: $140-145$

Katus HA, Remppis A, Scheffold T, Diederich KW, Kuebler W 1991: Intracellular compartmentation of cardiac troponin $\mathrm{T}$ and its release kinetics in patients with reperfused and nonreperfused myocardial infarction. Am J Cardiol 67: 1360-1367

Korff S, Katus HA, Giannitsis E 2006: Differential diagnosis of elevated troponins. Heart 92: 987-993

Ladenson JH 2007: A personal history of markers of myocyte injury [myocardial infarction]. Clinica Chimica Acta 381: 3-8

Mahammad Rahmathulla SB, Kodidhela Lakshmi Devi 2013: Origination and development of isoproterenolinduced myocardial infarction in male Wistar rats. Int Res J Pharm 4: 27-35

Ministry of Agriculture of the Czech Republic: Decree No 419/2012 Coll., on the protection of experimental animals, (Vyhláška 419/2012 Sb., o ochraně pokusných zvířat)

Mirvis DM, Ramanathan KB, Wilson JL 1986: Regional Blood Flow Correlates of ST Segment Depression in Tachycardia-induced Myocardial Ischemia. Circulation 73: 365-373

O'Brien PJ, Landt Y, Ladenson JH 1997: Differential reactivity od cardiac and skeletal muscle from various species in a cardiac Troponin I immunoassay. Clinical Chemistry 43: 2333-2338

O'Brien PJ, Smith DE, Knechtel TJ, Marchak MA, Pruimboom-Brees I, Brees DJ, Spratt DP, Archer FJ, Butler P, Potter AN, Provost JP, Richard J, Snyder PA, Reagan WJ 2006: Cardiac troponin I is a sensitive, specific biomarker of cardiac injury in laboratory animals. Lab Anim 40: 153-171

Ojha S, Nandave M, Arora S, Arya DS 2010: Effect of Isoproterenol on Tissue Defense Enzymes, Hemodynamic and Left Ventricular Contractile Function in Rats. Ind J Clin Biochem 25: 357-361

Parmacek MS, Solaro RJ 2004: Biology of the troponin complex in cardiac myocytes. Prog Cardiovasc Dis 47: $159-176$

Potse M, Coronel R, Falcao S, LeBlanc AR, Vinet A 2007: The Effect of Lesion Size and Tissue Remodeling on ST Deviation in Partial-thickness Ischemia. Heart Rhythm 4: 200-206

Reagan WJ 2010: Troponin as a biomarker of cardiac toxicity: Past, Present, and Future. Toxicologic Pathology 38: $1134-1137$

Rona G 1985: Catecholamine cardiotoxicity. J Mol Cell Cardiol 17: 291-306 
Rona G, Chappel CL, Balazs T, Gaudry R 1959: An infarcted-like myocardial lesion and other toxic manifestations produced by isoproterenol in the rat. Arch Pathol 67: 443-455

Schreier T, Kedes L, Gahlmann R 1990: Cloning, structural analysis, and expression of the human slow twitch skeletal muscle/cardiac troponin C gene. J Biol Chem 265: 21247-21253

Tappia PS, Heta T, Dhalla NS 2001: Role of oxidative stress in catecholamine-induced changes in cardiac sarcolemmal $\mathrm{Ca}^{2+}$ transport. Arch Biochem Biophy 377: 85-92

Walker DB 2006: Serum chemical biomarkers of cardiac injury for nonclinical safety testing. Toxicol Pathol 34: 94-104

Wells SM, Sleeper M 2008: Cardiac troponins. Journal of Veterinary Emergency and Critical Care 18: 235-245

Wu AHB, Feng YJ 1998: Biochemical differences between cTnT and cTnI and their signifikance for diagnosis of acute coronary syndromes. Eur Heart J 19: 25-29

Wu AHB, Wang XM, Gornet TG, Ordóñez-Llanos J 1992: Creatine kinase MB isoforms in patients with skeletal muscle injury: Ramifications for early detection of acute myocardial infarction. Clin Chem 38: 2397-2400

York M, Scudamore CH, Brady S, Chen CH, Wilson S, Curtis M, Evans G, Griffiths W, Whayman M, Williams T, Turton J 2007: Characterization of Troponin Responses in Isoproterenol-Induced Cardiac Injury in the Hanover Wistar Rat. Toxicol Pathol 35: 606-617

Zhang J, Knapton A, Lipshultz SE, Weaver JL, Herman EH 2008: Isoproterenol-induced cardiotoxicity in Sprague-Dawley rats: correlation of reversible and irreversible myocardial injury with release of cardiac troponin T and role of iNOS in myocardial injury. Toxicol Pathol 36: 277-288 